Disclosure of Interests: None declared

DOI: 10.1136/annrheumdis-2020-eular.5318

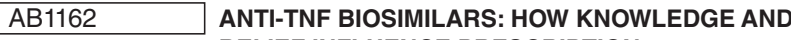 BELIEF INFLUENCE PRESCRIPTION}

A. De Chateaubriant ${ }^{1}$, P. Ingrand ${ }^{2}$, E. Gervais ${ }^{1,3} .{ }^{1}$ Poitiers University Hospital, Rheumatology, Poitiers, France; ${ }^{2}$ Poitiers University Hospital, Poitiers, France; ${ }^{3}$ University of Poitiers, LITEC, Poitiers, France

Background: Biological agents change the management of rheumatic inflammatory disease with improving care but increasing costs. Biosimilars for subcutaneous TNF inhibitors (SC TNFi) are available in France since 2015 and provide the same treatments at lower cost. French health agencies do not legally oblige rheumatologist to first prescribe or switch to biosimilars.

Objectives: To assess the knowledge and beliefs of French rheumatologists about biosimilars.

Methods: The assessment was developed with a questionnaire consisting of five parts: demographics data, professional practice, theoretical knowledge, beliefs and confidence. The questionnaire was administrated via the website Limesurvey and sent by email to French rheumatologist. A descriptive analysis of the data and associated factors to initiation and switch of biosimilars have been done.

Results: One hundred one rheumatologists have participated to the study. $47.1 \%$ was less than forty years old. $92 \%$ of them have the authorization to prescribe TNFi. 53.2 always prescribed a biosimilars when they prescribed a SC TNFi for the first time and $78.5 \%$ in $90 \%$ of cases. $30.6 \%$ of French rheumatologist never switched to a biosimilars. Those who switch, do it in more than $75 \%$ of cases. $96.5 \%, 87.1 \%$ and $91.8 \%$ respectively answered that biosimilars are as efficient, as safe and have the same immunogenicity profile compared to originator. The initial biosimilars prescription is associated with a better knowledge about biosimilars. For example, $77.4 \%$ of rheumatologist who prescribe in more than $90 \%$ of the case, answer NO to the question "biosimilars and originator have to be compared in a phase III study for EACH indications for which originator obtained marketing approval'. Only $31.2 \%$ of rheumatologist who prescribed in less than $90 \%$ of the case respond NO to this question. This difference was significant $p<0.001$. The switch to a biosimilars is associated with the beliefs and confidence. For example $25.4 \%$ of rheumatologists who switch for biosimilar in more than $75 \%$ of the case, answer YES to the question "There is not enough experiences with biosimilar.' $57.7 \%$ of rheumatologist who switched in less than $75 \%$ of the case respond YES to this question. This difference was significant $p<0.003$.

Conclusion: Despite good knowledge on biosimilars, some French rheumatologists do not switch for these molecules. Our study suggests that this is due to lack of confidence.

Acknowledgments: The authors thank French rheumatologist who answer to the questionnaire

Disclosure of Interests: Arnaud De Chateaubriant: None declared, Pierre Ingrand: None declared, Elisabeth Gervais Speakers bureau: Novartis, Janssen, Roche, Pfizer, BMS, Abbvie

DOI: 10.1136/annrheumdis-2020-eular.4174

\section{AB1163 IMPACT ON COSTS AND WORKING LIFE OF RHEUMATIC PATIENTS WITH CHANGE IN BIOLOGICAL THERAPY FOR NO MEDICAL REASONS. REAL LIFE EXPERIENCE IN REGIONAL HOSPITAL OF SOCIAL SECURITY}

L. Pablo Olivares ${ }^{1}$, E. González Figueroa ${ }^{2}$, M. F. López Marquet ${ }^{1}$, M. V. Goycochea Robles ${ }^{3} .{ }^{1}$ IMSS, Rheumatology external consult, Mexico City, Mexico; ${ }^{2}$ IMSS, Clinial Research Unit HGR 1, Benito Juarez, Mexico; ${ }^{3}$ UNAM, Departamento de Enseñanza Clínica Facultad de Medicina, Coyoacan Mexico City, Mexico

Background: Biologics as new therapeutic alternatives have revolutionized the management of rheumatic diseases. Biosimilars have been emerged as less expensive alternative. Most part of evaluations of biosimilars had proved effectiveness by clinical trials with outcomes as remission, but specific social aspects and economic variables not always has been considered. These aspects must be assessed in specific and real contexts (countries, health institutions) The effect on non-medical switch of biological therapy for rheumatic diseases in costs and working variables has not been documented in patients of the Mexican Socia Security Institute (IMSS)

Objectives: Evaluate the impact of the change of biological therapy for non-medical reasons on the economic variables, costs and working aspects with rheumatic diseases on Mexican patients with social security

Methods: Cross-sectional observational study included patients from rheumatology clinical service of an IMSS Regional Hospital in Mexico City during last trimester of 2018. A structured questionnaire was applied who diagnosis of rheumatoid arthritis and spondyloarthropathies where received treatment biological for at least 24 months prior to the study. The individuals were divided into two comparison groups, G1: patients who changed to biosimilar biological treatment for non-medical reasons and G2: patients with original biological treatment without changes in the therapeutic scheme. In addition to socio-demographic characteristics, functional capacity (HAQ-di), disease activity (DAS28) and labo aspects were evaluated. A sex and age adjusted logistic regression analysis was performed where the outcome variable was the evolution

Results: The 71 cases evaluated included $90 \%$ female with schooling $>9$ years in $90 \%$. Gl included $49 \%$, age 51.1 years \pm 15.1 vs G2 $55.8+12.7$; evolution in years: Gl: $13.8+4.7$ vs Gll: $9.74+5.97$. Both groups persisted in remission by DAS28 (G1:2.50+0.489 VS G2: $2.39+0.63)$. The G1 had a higher percentage of moderate affection in functional capacity: $58.8 \%$ vs G2: $35.9 \%$, required more travel time to work, 2 hours less work per day and required more disability (48\% vs 43\% [RM0 $1.695 \% \mathrm{Cl}: 0.45-3.4]$ After logistic regression models adjusted by age and sex, no significant results were found for economic and costs variables. However, a statistically significant association $(\mathrm{p}=0.017)$ were found for time progression disease as predictor variable between $\mathrm{G} 1 \mathrm{Vs}$ Group $2(\mathrm{OR}=1.15,95 \% \mathrm{Cl} 1.02,1.30)$. Mean time progression disease for $\mathrm{G} 1$ were $9.38 \pm 6.5$ years $(n=43)$ and for $\mathrm{G} 2$ were $14.17 \pm 5.5$ years $(n=28)$

Conclusion: IMSS rheumatic patients who were on their original biological treatment, had more working time and improved statistically significative their time progression disease. Switch to biosimilar not have impact in clinical remission but can impact in economic and working aspects. IMSS serves $50 \%$ of Mexican population, covering medical care (physician fees, laboratory and medication purchase), and social security; so, should consider not only clinical aspects to acquisition of biologics drugs

Acknowledgments: FUNDACION IMSS

Disclosure of Interests: None declared

DOI: 10.1136/annrheumdis-2020-eular.6301

\section{AB1164 \\ A COST PER RESPONDER ANALYSIS OF ABATACEPT VERSUS ADALIMUMAB FOR THE TREATMENT OF RHEUMATOID ARTHRITIS AMONG PATIENTS WITH SHARED EPITOPE (SE) POSITIVITY FROM A UNITED STATES PAYER PERSPECTIVE}

S. H. Park' ${ }^{1}$ X. Han ${ }^{2}$, F. Lobo ${ }^{2}$, S. Nanji1 , D. Patel ${ }^{1} .{ }^{1}$ Pharmerit International, Bethesda, United States of America; ${ }^{2}$ Bristol-Myers Squibb, Lawrence

Township, United States of America

Background: The shared epitope (SE) is a significant genetic risk factor for rheumatoid arthritis (RA), and it has been proposed to be associated with T-cel activation and the production of anti-citrullinated protein antibody (ACPA). ${ }^{1-3}$ The results from the Early AMPLE trial, a head-to-head trial comparing the efficacy of abatacept versus adalimumab among early moderate-to-severe RA patients with positive ACPA $(A C P A+)$ and rheumatoid factor (RF), showed that at week 24, patients with SE positivity (SE+) responded better to abatacept compared to adalimumab across all efficacy measures evaluated (ACR20 [American College of Rheumatology], ACR50, ACR70, DAS[disease activity score]28-CRP[C-reactive protein]). ${ }^{4}$

Objectives: To compare the cost per responder (CPR) between abatacept and adalimumab among RA patients with SE+ at week 24 using the Early AMPLE trial data from a United States (US) payer perspective.

Methods: A CPR analysis was conducted for RA patients with $\mathrm{SE}_{+}, \mathrm{ACPA}+$, and RF. Responders were defined as patients achieving ACR20, ACR50, ACR70 or DAS28-CRP $\leq 2.6$ and efficacy data was sourced from the trial (Figure 1). ${ }^{4}$ Approved product labels were referenced for treatment dosing regimen and wholesale acquisition cost was used to calculate pharmacy cost. ${ }^{5} \mathrm{~A}$ real-world rebate scenario was considered for adalimumab (30\%) to reflect the real-world pricing in the US market. The CPR was calculated as the total pharmacy cost divided by the proportion of responders.

Results: The total pharmacy cost at week 24 was $\$ 26,273$ per patient for abatacept and $\$ 21,731$ per patient for adalimumab. With achieving ACR70 as the definition of responder, the CPR at 24-week was $\$ 46,337$ for abatacept and $\$ 74,935$ for adalimumab, a difference of $\$ 28,598$ (Table 1 ). The CPR was consistently lower for abatacept compared to adalimumab across all clinical measures, with difference ranging from $\$ 7,099$ to $\$ 43,609$.

Table 1. Overall cost per responder results

\begin{tabular}{cccc}
\hline & Abatacept & Adalimumab & Difference \\
\hline ACR20 & $\$ 30,303.74$ & $\$ 37,403.06$ & $-\$ 7,099.32$ \\
ACR50 & $\$ 34,254.68$ & $\$ 48,077.83$ & $-\$ 13,823.15$ \\
ACR70 & $\$ 46,337.46$ & $\$ 74,935.10$ & $-\$ 28,597.64$ \\
DAS28-CRP $\leq 2.6$ & $\$ 52,546.68$ & $\$ 96,155.65$ & $-\$ 43,608.97$
\end{tabular}


Conclusion: While the pharmacy cost was higher for abatacept compared to adalimumab driven by the rebate, due to its higher clinical efficacy, the CPR was consistently lower for SE+ RA patients treated with abatacept. The results may be useful for US healthcare decision makers in understanding how to optimize treatment for SE+ RA patient while minimizing costs in today's budget constrained environment.

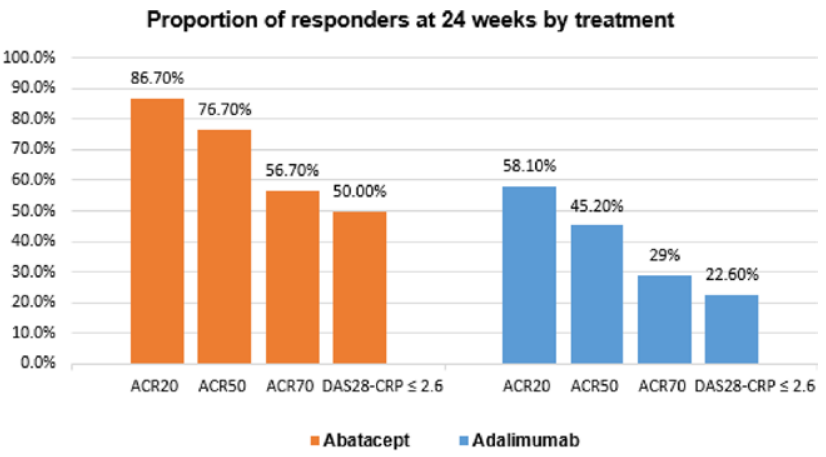

Figure 1. Proportion of responders by treatment data from the Early AMPLE trial

References:

[1] Gregersen PK, Silver J, Winchester RJ. The shared epitope hypothesis. An approach to understanding the molecular genetics of susceptibility to rheumatoid arthritis. Arthritis and rheumatism. 1987;30(11):1205-13.

[2] Holoshitz J. The rheumatoid arthritis HLA-DRB1 shared epitope. Curr Opin Rheumatol. 2010;22(3):293-8.

[3] Sakkas LI, Bogdanos DP, Katsiari C, et al. Anti-citrullinated peptides as autoantigens in rheumatoid arthritis-relevance to treatment. Autoimmun Rev. 2014;13(11):1114-20.

[4] Fleischmann R, Weinblatt M, Ahmad H, et al. Efficacy of abatacept and adalimumab in patientsn with early rheumatoid arthritis with multiple poor prognostic factors: post hoc analysis of a randomized controlled clinical trial (AMPLE). Rheumatol Ther. 2019;6(4): 559-571.

[5] Truven Health Analytics. Redbook online. Accessed October 11, 2019

Disclosure of Interests: Sang Hee Park Consultant of: Pharmerit International, which received consultancy fees from Bristol-Myers Squibb (US), Inc. for this study, Xue Han Employee of: BMS, Francis Lobo Shareholder of: Bristol-Myers Squibb (US), Employee of: Bristol-Myers Squibb (US), Sakina Nanji Consultant of: Pharmerit International, which received consultancy fees from Bristol-Myers Squibb (US), Inc. for this study, Dipen Patel Consultant of: Pharmerit International, which received consultancy fees from Bristol-Myers Squibb (US), Inc. for this study

DOI: 10.1136/annrheumdis-2020-eular.1019

\section{AB1165 MEDICATION ADHERENCE DATA IN A RANDOMIZED TRIAL: LARGE CHALLENGES TO COME FROM RAW DATA TO A WORKABLE AND RELIABLE DATASET}

L. Hartman $^{1,2}$, E. Alessandri ${ }^{3}$, R. Bos ${ }^{4}$, D. Opris-Belinski ${ }^{5}$, M. R. Kok ${ }^{6}$, H. GriepWentink $^{7}$, R. Klaasen ${ }^{8}$, C. Allaart ${ }^{9}$, G. Bruyn ${ }^{10}$, H. Raterman ${ }^{11}$, M. Voshaar ${ }^{12}$, N. Gomes ${ }^{13}$, R. Pinto ${ }^{14}$, T. Klausch ${ }^{2}$, W. Lems ${ }^{1}$, M. Boers ${ }^{1,2}$. ${ }^{1}$ Amsterdam Rheumatology and Immunology Center, location VUmc, Amsterdam, Netherlands; ${ }^{2}$ Amsterdam UMC, location VUmc, Epidemiology \& Biostatistics, Amsterdam, Netherlands; ${ }^{3}$ University of Genoa, Genoa, Italy; ${ }^{4}$ Medical Center Leeuwarden, Leeuwarden, Netherlands; ${ }^{5}$ University of Medicine and Pharmacy 'Carol Davila", Bucharest, Romania; ${ }^{6}$ Maasstad Hospital, Rotterdam, Netherlands; ${ }^{7}$ Antonius Ziekenhuis, Sneek, Netherlands; ${ }^{8}$ Meander Medical Center, Amersfoort, Netherlands; ${ }^{9}$ LUMC, Leiden, Netherlands; ${ }^{10}$ MC Groep, Lelystad, Netherlands; ${ }^{11}$ Noordwest Ziekenhuisgroep, Alkmaar, Netherlands; ${ }^{12}$ Tools, Amsterdam, Netherlands; ${ }^{13}$ Exatronic, Aveiro, Portugal; ${ }^{14}$ Bluepharma, Coimbra, Portugal

Background: Medication adherence in the GLORIA trial, among elderly patients with rheumatoid arthritis, is measured with caps that register openings of the medication bottle. At each study visit, one or two medication bottles with cap (kits) are dispensed, each containing 90 capsules. Multiple steps are needed to come to a workable dataset to describe adherence.

Objectives: To describe the steps that are needed to come from raw data to a workable dataset to analyze adherence data that are recorded by electronic caps.

Methods: The medication bottle contains a cap with the ability to register cap openings. The raw dataset from the caps consist of an excel file with one opening event per row, recorded as date and time. One cap yields approximately 90 rows. First, the kit numbers were matched to the corresponding patient numbers, that are recorded in another excel file. Instances where two kits were dispensed were recorded with two kit numbers in one cell and need to be copied to two cells with one kit number. Second, the VLOOKUP function was used to combine dates and kit numbers. One row now contains all openings from one kit. Then, the number of days between first opening and each next opening date was calculated. A range of 90 days was made to calculate how many times the bottle was opened on each day of the 90-days period. The results were color-coded to visualize instances of zero, one or $\geq$ two openings on a day.

Results: The colored calendar matrix (Figure 1) can now be used to categorize adherence patterns.

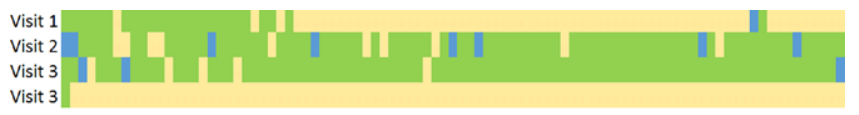

Figure 1. Example of calendar matrix of four caps of one patient.

Yellow=no opening, green=1 opening, blue=22 openings.

Conclusion: A monitoring cap seems a simple instrument to measure adherence. However, multiple steps and a lot of time are needed to come to a workable dataset for the study of adherence patterns.

Acknowledgments: The GLORIA project is funded by the European Union's Horizon 2020 research and innovation programme under the topic "Personalizing Health and Care", grant agreement No 634886.

Disclosure of Interests: Linda Hartman: None declared, Elisa Alessandri None declared, Reinhard Bos: None declared, Daniela Opris-Belinski Speakers bureau: as declared, Marc R Kok Grant/research support from: BMS and Novartis, Consultant of: Novartis and Galapagos, Hanneke Griep-Wentink: None declared, Ruth Klaasen: None declared, Cornelia Allaart: None declared, George Bruyn: None declared, Hennie Raterman Grant/research support from: UCB, Consultant of: Abbvie, Amgen, Bristol-Myers Sqibb, Cellgene and Sanof Genzyme, Marieke Voshaar Grant/research support from: part of phd research, Speakers bureau: conducting a workshop (Pfizer), Nuno Gomes: None declared Rui Pinto: None declared, Thomas Klausch: None declared, WIllem Lems Grant/ research support from: Pfizer, Consultant of: Lilly, Pfizer, Maarten Boers: None declared

DOI: 10.1136/annrheumdis-2020-eular.3638

\begin{tabular}{|l|l|}
\hline AB1166 & DETERMINANTS OF REPOSITORY CORTICOTROPIN \\
INJECTION TREATMENT INITIATION FOR PATIENTS \\
WITH RHEUMATOID ARTHRITIS IN A LARGE CLAIMS \\
DATABASE
\end{tabular}

K. Hayes ${ }^{1}$, M. Panaccio ${ }^{2}$, H. Zhou ${ }^{3}$, M. Fahim ${ }^{3} .{ }^{1}$ Mallinckrodt Pharmaceuticals, Hazelwood, MO, United States of America; ${ }^{2}$ Mallinckrodt Pharmaceuticals, Bedminster, NJ, United States of America; ${ }^{3}$ KMK Consulting Inc, Morristown, NJ, United States of America

Background: The treatment goal in rheumatoid arthritis (RA) is sustained remission and prevention of RA flares [1]. While targeted biologics have improved disease outcomes, almost one-third of patients (pts) discontinue treatment by 1 year and $50 \%$ by 2 years, with lack of efficacy as the most common reason [2] Repository corticotropin injection $(\mathrm{RCl})$ is a naturally sourced complex mixture of adrenocorticotropic hormone analogues and other pituitary peptides and is an agonist for all 5 melanocortin receptors (MCRs). Activation of MCRs by $\mathrm{RCl}$ has been shown to have direct and indirect anti-inflammatory and immunomodulatory effects. $\mathrm{RCl}$ is indicated for adjunctive therapy for short-term administration in RA flares or uncontrolled disease [3]

Objectives: To characterize RA pts that initiate $\mathrm{RCl}$ therapy and identify predictors of $\mathrm{RCl}$ initiation, compared to biologic disease-modifying antirheumatic drugs (DMARDs).

Methods: This retrospective cohort study identified pts with ICD-9/10 diagnosis for RA over an 11-year period (2008-2018) in a large claims database (Truven MarketScan $\AA$ ). Adults with $\geq 1$ claim for $\mathrm{RCl}$ ( $\mathrm{RCl}$ cohort) or $\geq 1$ RA-related biologic claim but no $\mathrm{RCl}$ (non- $\mathrm{RCl}$ cohort) were selected and characterized by demographics, disease severity (Claims-based Index for RA Severity, CIRAS), comorbidities (Charlson Comorbidity Index, CCI), treatment patterns, and healthcare resource utilization in the 12-month baseline $(\mathrm{BL})$ period prior to their index date (i.e., the $1^{\text {st }} \mathrm{RCl}$ claim or last claim for biologic for non- $\mathrm{RCl}$ cohort). Predictors of $\mathrm{RCl}$ initiation were identified by multivariable logistic regression, controlling for demographics and BL characteristics.

Results: A total of 393 pts initiated $\mathrm{RCI}$ therapy while 188,062 initiated biologic treatment with no $\mathrm{RCl}$ claims. At $\mathrm{BL}$, cohorts were similar with respect to mean age ( 56 years), gender (76-79\% female), and insurance type (79-80\% commercial). Cohorts differed by region, plan type, and index year. Compared to non- $\mathrm{RCl}$ 